\title{
4 Channel Sterilizer Calibrator
}

\author{
Syafiq Naufal Syayakti ${ }^{\#}$, Endang Dian Setioningsih, Sumber \\ Department of Electromedical Engineering Poltekkes Kemenkes, Surabaya \\ Jl. Pucang Jajar Timur No. 10, Surabaya, 60245, Indonesia \\ "syafiqnaufals@gmail.com,dian18@poltekkesdepkes-sby.ac.id, sumber@poltekkesdepkes-sby.ac.id,
}

\begin{abstract}
Thermocouple (Thermocouple) is a type of temperature sensor used to detect or measure temperature through two types of metal conductors, whose working principle is that each end of a metal conductor is combined to create a "Thermoelectric" effect. One type of metal conductor contained in a thermocouple will serve as a reference with a constant temperature (fixed), while a metal conductor functions as a metal conductor that detects hot temperatures. Sterilisator is a device used to sterilize medical instruments to avoid the bacteria that attach to the remainder of the use of medical instruments. The temperature of the sterilizer varies but generally for dry sterilizers ranges from $175^{\circ}$ Celsius. From the above problems, the author wants to develop a "4 Channel Sterilizer Calibrator", Using the Arduino Nano Atmega328 as a minimum system, K type thermocouple and MAX6675 module as a sensor. Measurements were made by comparing modules with standard measuring instruments, obtained the smallest error $0.2 \%$ at $\mathrm{T} 3$ and $\mathrm{T} 4$ when measuring $100{ }^{\circ} \mathrm{C}$, and the largest $4.4 \%$ at $\mathrm{T} 2$ when measuring $150^{\circ} \mathrm{C}$.
\end{abstract}

Keywords-Thermocouple; Sterilisator; Arduino

\section{INTRODUCTION}

Thermocouple (Thermocouple) is a type of temperature sensor used to detect or measure temperature through two types of metal conductors, whose working principle is that each end of a metal conductor is combined to create a "Thermoelectric" effect [1]. One type of metal conductor contained in a thermocouple will function as a reference with a constant temperature (fixed), while a metal conductor functions as a metal conductor that detects hot temperatures [1].

Dwinta Mussetyarsih did a research on "Data Logger Temperature Meter on Autoclave". The temperature sensor is used LM35 as a sensor that converts heat into an electrical signal. This signal will be processed in the microcontroller circuit. In processing data to be able to store and displayed on the display, the author use IC Atmega328 as a micro processor. Based on the results of measuring $60^{\circ}$ to $100^{\circ}$ on the autoclave using a temperature calibrator, an error of $0.43 \%$ was obtained. [2] [2].

In 2016, Dwinta Mussetyarsih's research was continued by Rizky Bian Primaswara with the title "Data Logger Temperature Meter in Dry Sterilisator". To record temperature data on sterilizers using 2 temperature sensors placed in the sterilizer in the right and left positions, with a temperature range of $50^{\circ} \mathrm{C}$ to $170^{\circ} \mathrm{C}$, using the thermocouple temperature sensor. There is a difference between the setting temperature and the module temperature reading to $3{ }^{\circ} \mathrm{C}$ at $50{ }^{\circ} \mathrm{C}, 150^{\circ} \mathrm{C}$ and $200^{\circ} \mathrm{C}$. [3]

Sterilisator is a device used to sterilize medical instruments to avoid the bacteria that attach to the rest of the use of medical instruments. The temperature of the sterilizer varies but generally for dry sterilizers range from $175^{\circ}$ Celsius. The working method of a temperature calibration device is to use a thermocouple sensor that is inserted into the device to be measured then the temperature results will be read. Temperature results are displayed on a $4 \times 16 \mathrm{LCD}$, the measurement data from a temperature calibration device shows the smallest percentage percentage of $0 \%$ at temperatures of 200,90 and $60^{\circ} \mathrm{C}$. [1]

Research conducted by Dan Liu et al. Found that the p-type thermocouple and n-type they design showed thermoelectric voltage of $410.3 \mathrm{mV}$ at $1270{ }^{\circ} \mathrm{C}$ and high sensitivity was 341.5 $\mu \mathrm{V} /{ }^{\circ} \mathrm{C}$. Thermocouple also shows very stable thermal output and reproducibility. This type of thermocouple opens a new path to designing high sensitivity thermal sensors for applications in accurate temperature sensing at high temperatures and harsh environments. [4]

In 2017, Indra Kumar Purohit did a study entitled "Temperature Mapping of Hot Air Sterilizers", in the study results obtained that the sterilization process used during the study was carried out at temperatures ranging from $250 \pm 15^{\circ}$ C. All results found in the acceptance criteria and this study was successful. The researcher concluded that dry heat sterilization is eligible for operation and performance. [5]

\section{MATERIALS AND METHODS}

\section{A. Experimental Setup}

This study uses a dry sterilizer (Elektro-Mag M6040P) as a temperature conditioner. Data collection is done 6 times. The results of reading the data are compared with a standard calibrator (Madgetech OctTemp2000).

\section{1) Materials and Tool}

This study used 4 type $\mathrm{K}$ thermocouples. Each of these thermocouples is connected to the MAX6675 module. Arduino nano is used to process data received from the MAX6675 module. A 4 × 20 LCD is used as a display.

\section{Indonesian Journal of Electronics, Electromedical, and Medical Informatics (IJEEEMI)}




\section{2) Experiment}

In this study, after the design was completed then measuring the signal output from the temperature reading of the MAX6675 module using an oscilloscope. The results of the module temperature readings were compared to standard sterilizer calibrator at $50^{\circ} \mathrm{C}, 100^{\circ} \mathrm{C}$ and $150^{\circ} \mathrm{C}$.

\section{B. The Diagram Block}

In this research, this module uses thermocouple to get a temperature value. The output from thermocouple processed using MAX6675 to convert the output from thermocouple to digital data which is processed by Arduino later to be converted into Celsius quantities. The results of processing the temperature values from Arduino are displayed to the display.

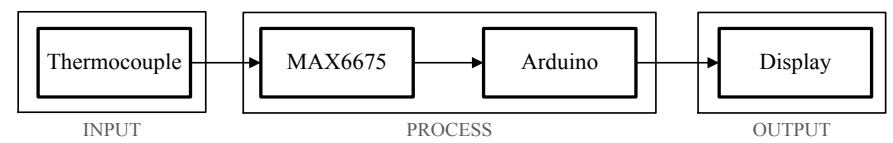

Fig. 1. The diagram block of the sterilizer calibrator

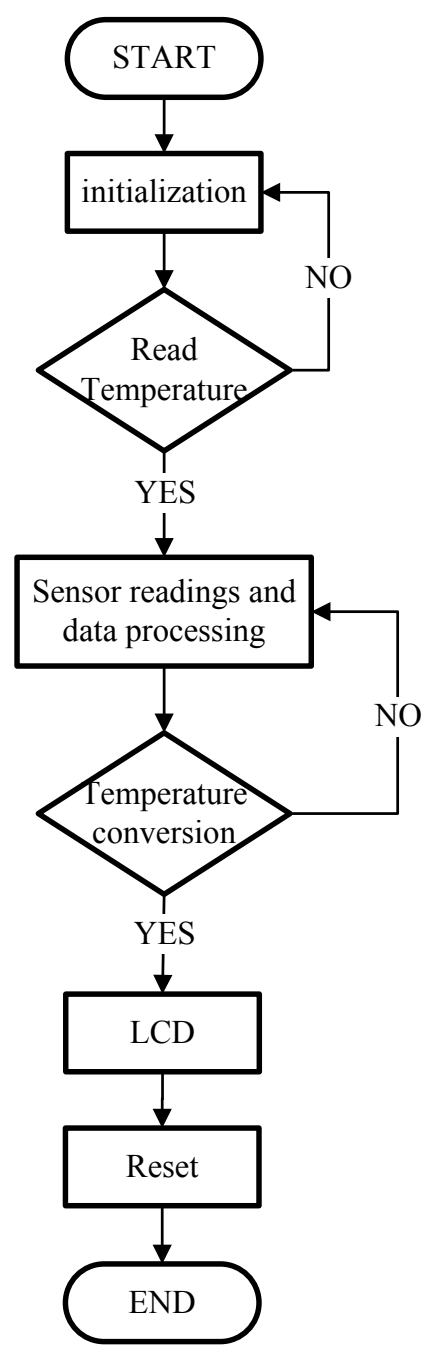

Fig. 2. The Flowchart of the Arduino Program

\section{The Flowchart}

The Arduino program was built on the flowchart as shown in Fig. 2. The process starts with initializing the program. Then measuring the temperature then the output data from the Arduino processed sensor to convert to the unit used $\left({ }^{\circ} \mathrm{F},{ }^{\circ} \mathrm{C}\right.$, ${ }^{\circ} \mathrm{K}$ ) then displayed to the LCD display.

\section{The Circuit}

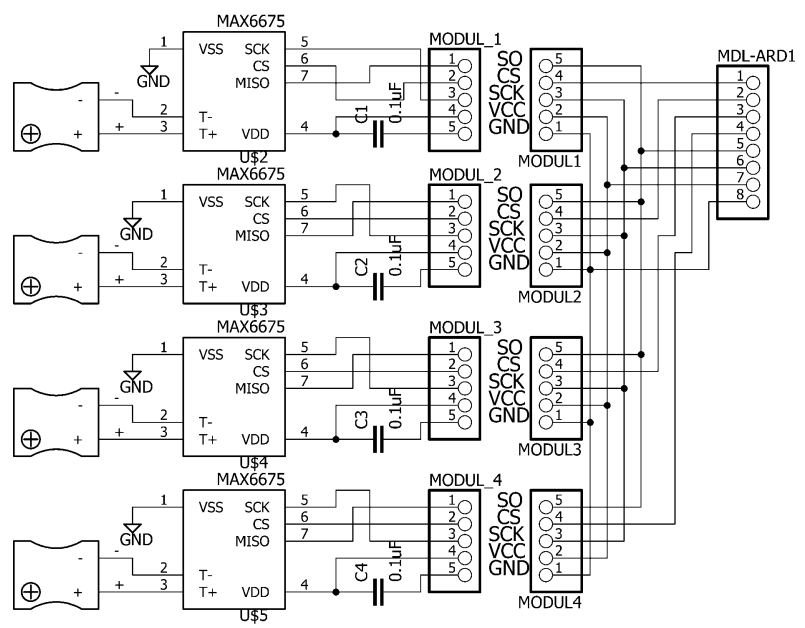

Fig. 3. Circuit

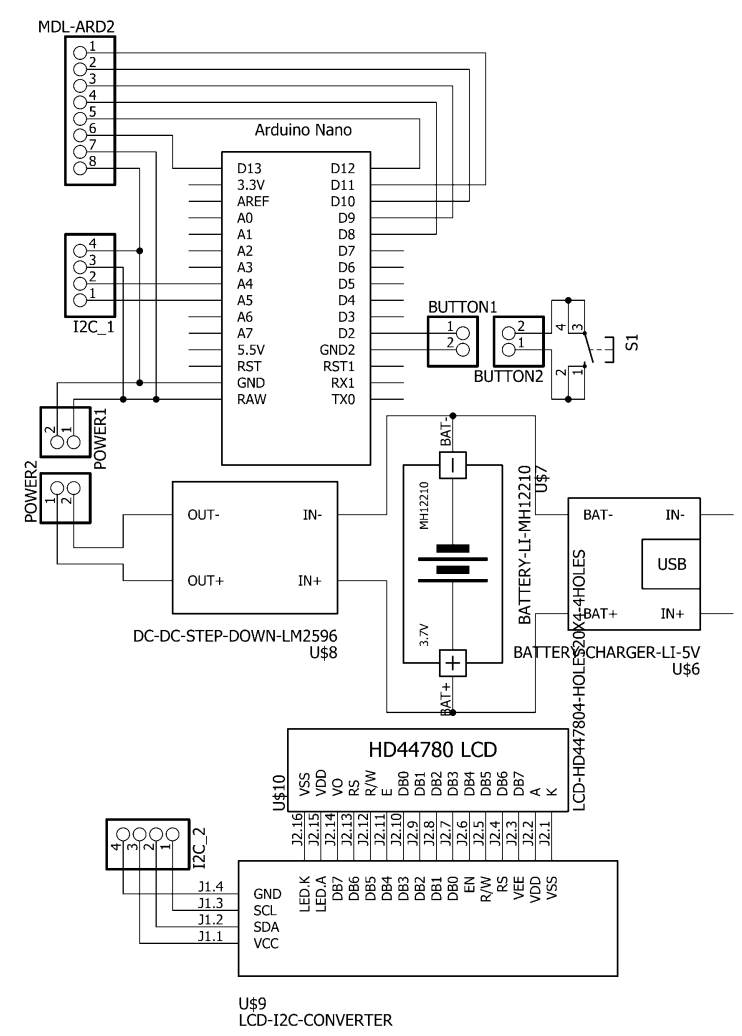

Fig. 4. Circuit 
In the initial condition the circuit does not get power from the battery. When the power button is pressed, the author's name and name of device will appear on the LCD. Then if the button is pressed again it will start the temperature measurement using the MAX6675 module which is connected to the microcontroller through the SDA and SCL pins. SDA is used to transmit data, while SCL is to transfer clock.

\section{1) Module MAX6675}

MAX6675 sensor consists of 5 pins, as follows:

1. SO : the sensor output data reading pin that is sent to the microcontroller.

2. CS : in a low position and receiving clock signal, the module will read the data, and will end the reading when CS returns high.

3. SCK : a pin that carries clock information between the module and microcontroller.

4. VCC : the pin on the module that is connected with a positive voltage.

5. GND : pin on the module that is connected to ground.

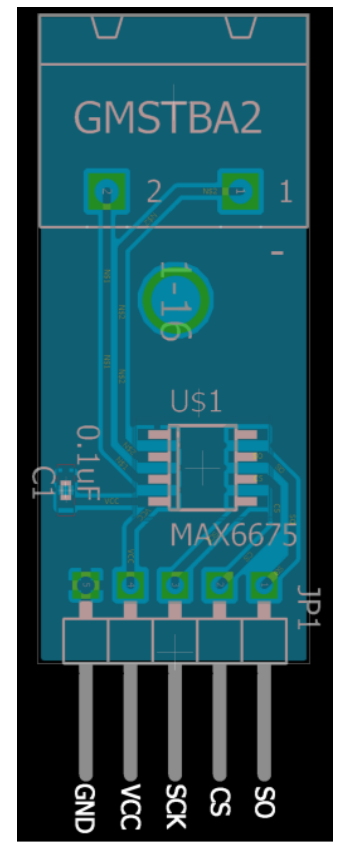

Fig. 5. Module MAX6675

\section{RESULTS}

In this study, the device was tested by reading the temperature on the dry sterilizer (Ellectro-Mag M6040P) and comparing the results with the temperature reading from the standard calibrator (Madgetech OctTemp2000).

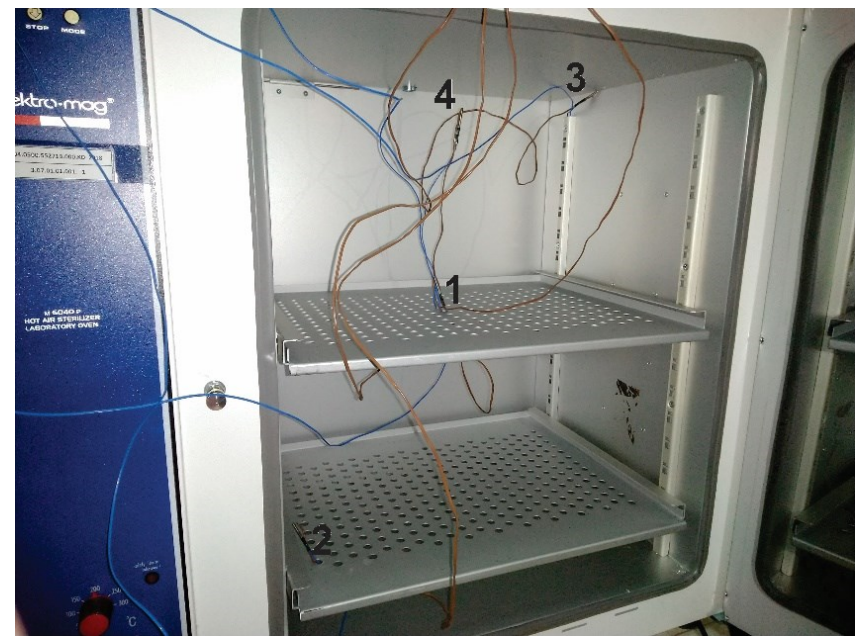

Fig. 6. Censor placement

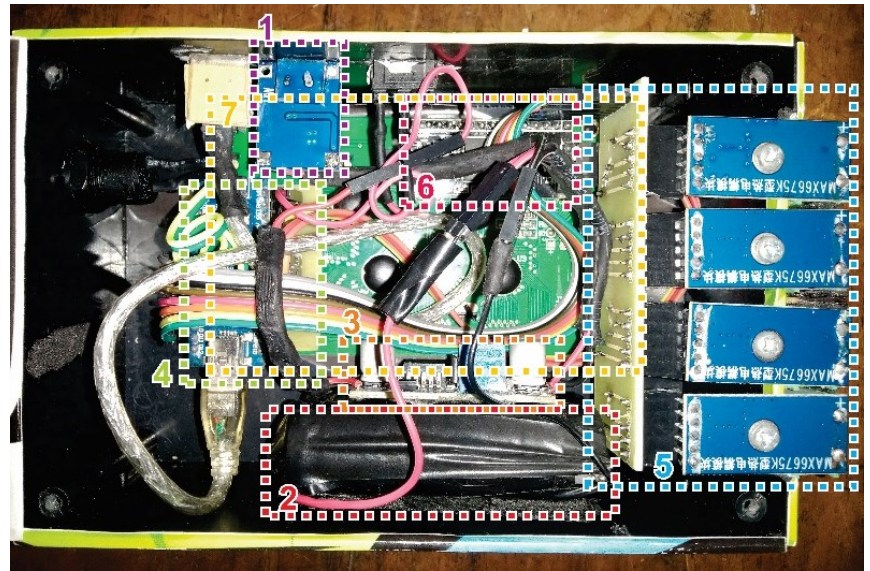

Fig. 7. Circuit design

1) 4 Channel Sterilizer Calibrator Design

This sterilizer calibrator uses a type 18650 battery (2) as a power source. The battery can be recharged using a charger module (1) by connecting to a DC $5 \mathrm{~V}$ voltage source via micro USB. The battery voltage goes into the step up module (3) to stabilize and adjust the input voltage that powering Arduino (4) at a $5 \mathrm{~V}$ DC value. Arduino (4) is used to process the temperature measurement data sent from the MAX6675 (5) module to be displayed to LCD (7) through I2C communication using the LCD I2C module (6).

\section{2) The Listing Program for 4 Channel Sterilizer Calibrator}

Listing program 1. Program to read sensors in Celsius

$$
\begin{aligned}
& \text { if }(\text { datamode }==1)\{ \\
& \text { lcd.clear }() ;
\end{aligned}
$$

\section{Indonesian Journal of Electronics, Electromedical, and Medical Informatics (IJEEEMI)}




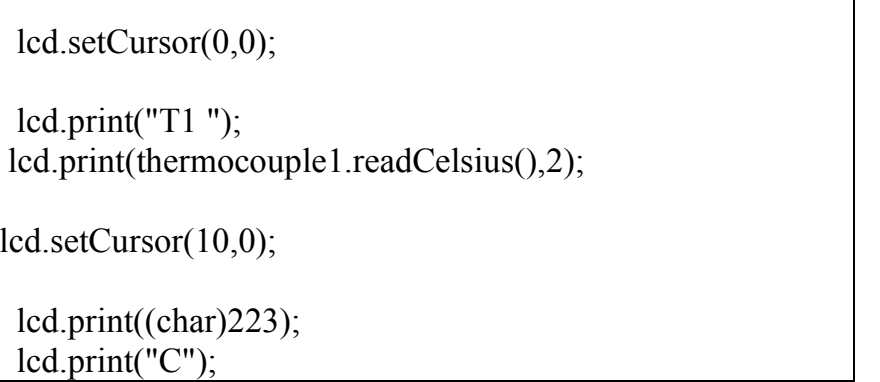

Lcd.print (thermocouple1.readCelsius (), 2); in the program section above is a command to display the variable value of thermocouple1 obtained from module 1 in a Celsius unit reading. "..., 2);" in program above is a command to display values with accuracy of 2 numbers behind comma.

2. Program to read sensors in kelvin units

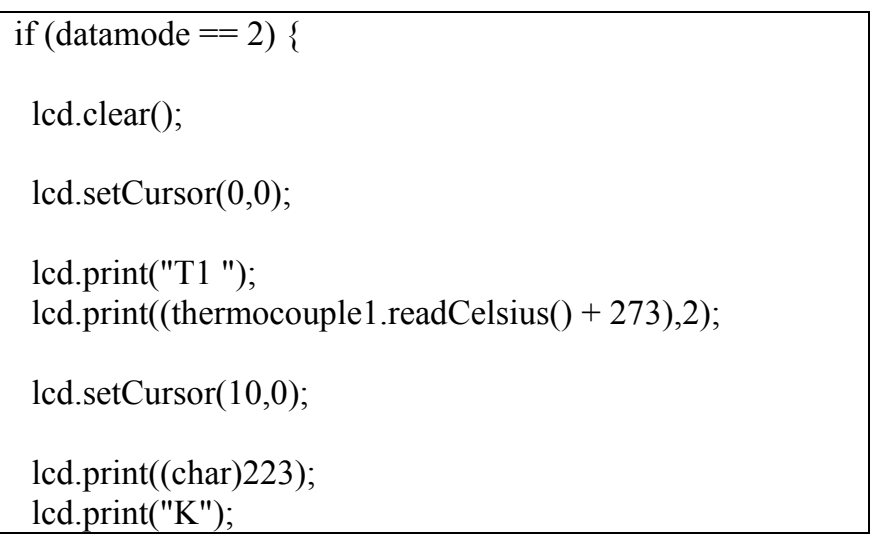

Lcd.print (thermocouple1.readCelsius ()$+273)$, 2); in the program section above is a command to display the variable value of thermocouple1 obtained from module 1 with a unit reading of Celsius. The value obtained is then added 273 to obtain the temperature value in Kelvin units. "..., 2);" in program above is a command to display values with accuracy of 2 numbers behind comma.

3. Program to read sensors in Fahrenheit units

if $($ datamode $==3)$;
lcd.clear () ;
lcd.setCursor $(0,0)$;
lcd.print("T1 ");
lcd.print $((($ thermocouple1.readCelsius ()$* 1.8)+32), 2) ;$
lcd.setCursor $(10,0)$;
lcd.print((char)223);

\section{lcd.print("F");}

Lcd.print (thermocouple1.readCelsius ()$* 1.8)+32), 2$ ); in the program section above is a command to display the variable value of thermocouplel obtained from module 1 with a unit reading of Celsius. The value obtained is then multiplied by 1.8 then added 32 to get the temperature value in Farenheit units. "..., 2);" in program above is a command to display values with accuracy of 2 numbers behind comma.

\section{3) MAX 6675 output signal}

Measurements are made on SO, SCK and CS pins in each module using an oscilloscope.

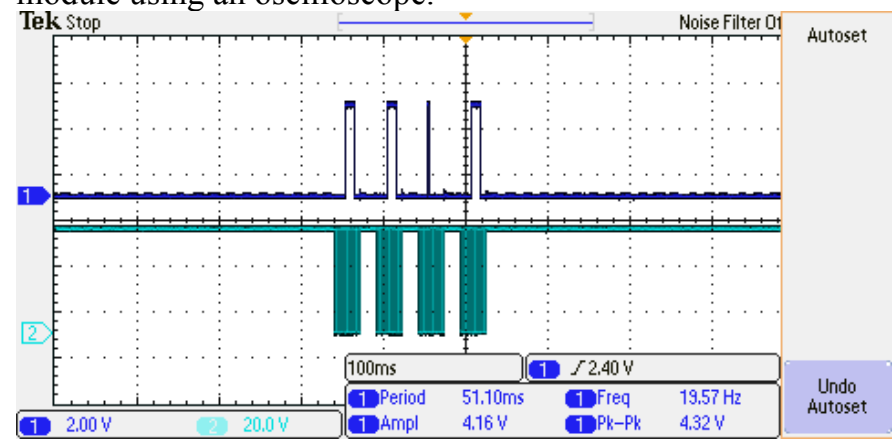

Fig. 8. Measurement results of SO and SCK pins in module 1

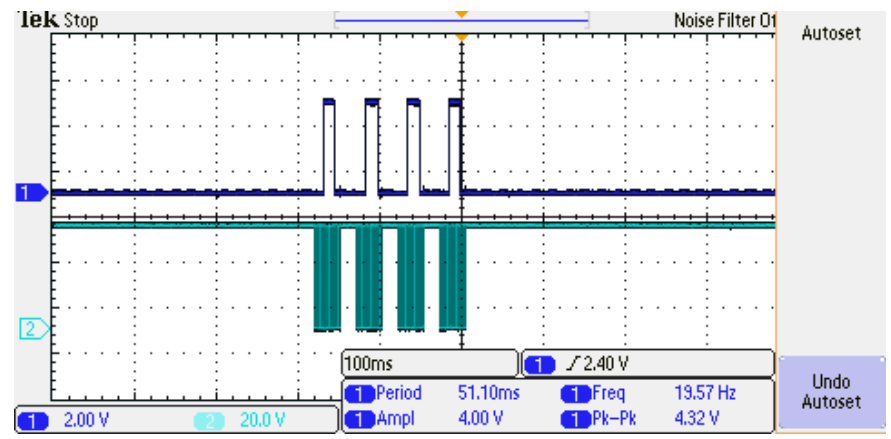

Fig. 9. Measurement results of SO and SCK pins in module 2

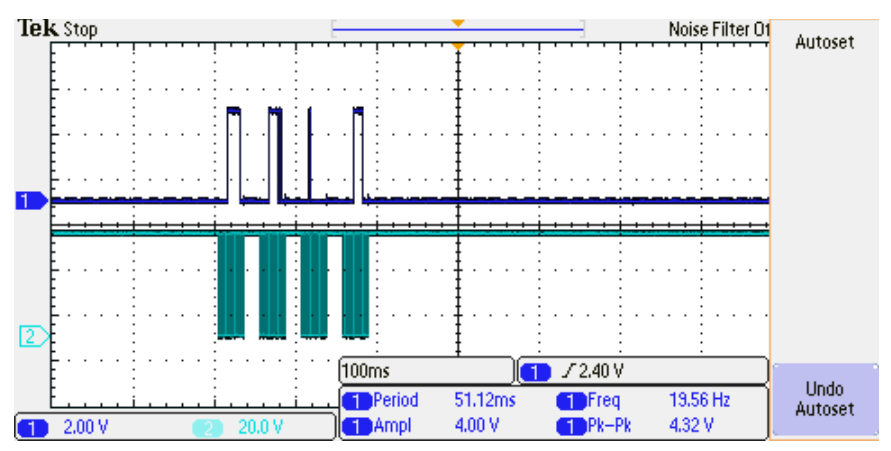

Fig. 10. Measurement results of SO and SCK pins in module 3 
IJEEMI, Vol. 1, No. 2, November 2019, pp:65-70

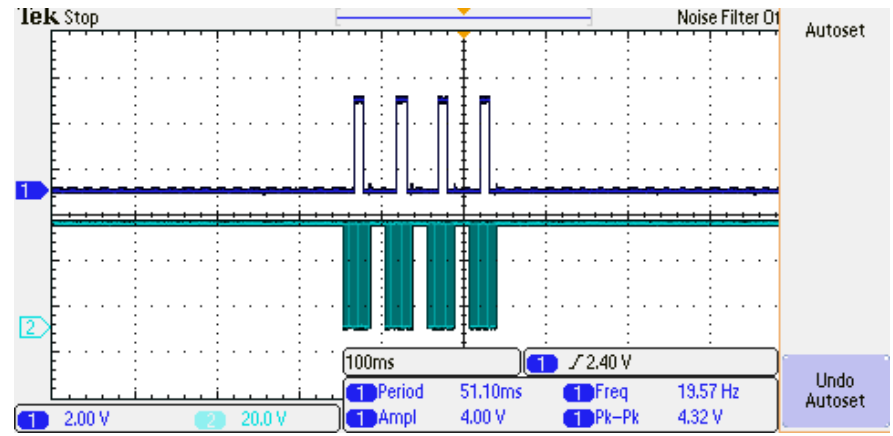

Fig. 11. Measurement results of SO and SCK pins in module 4

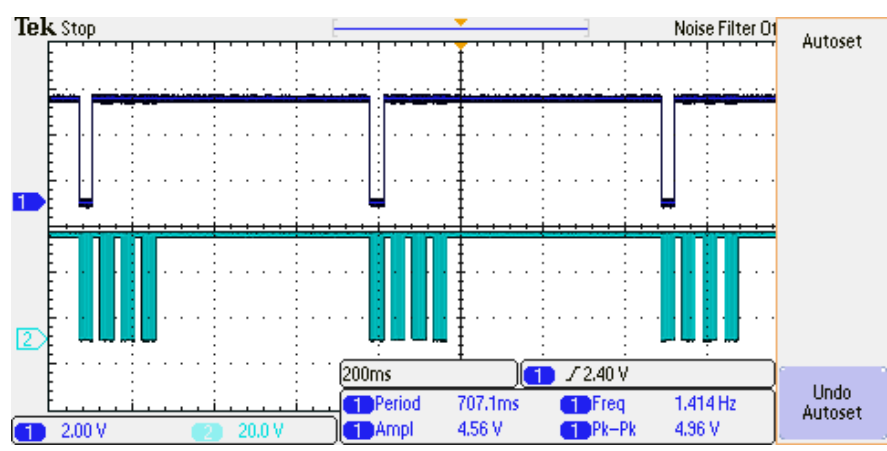

Fig. 12. Measurement results on CS and SCK pins in module 1

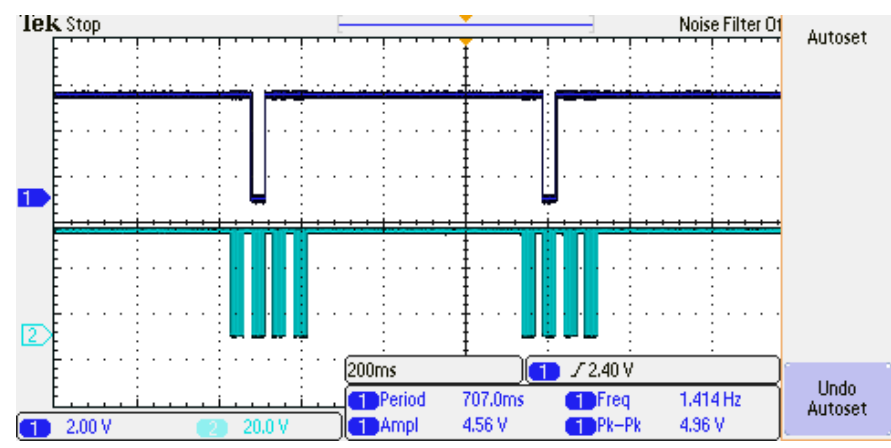

Fig. 13. Measurement results on CS and SCK pins in module 2

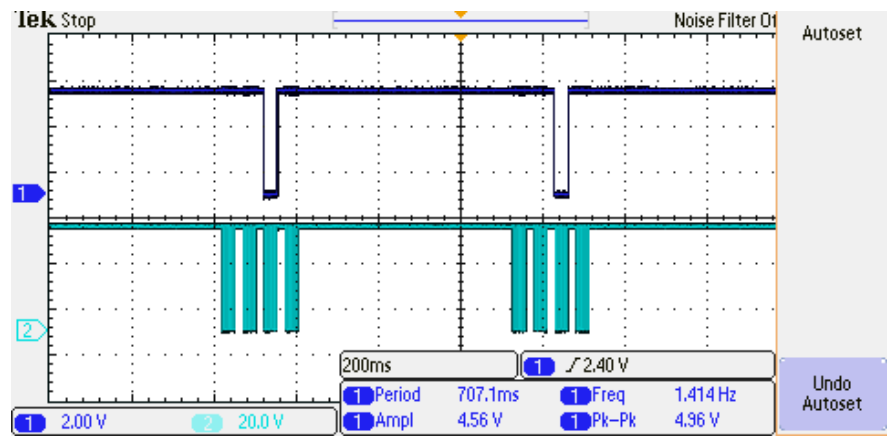

Fig. 14. Measurement results on CS and SCK pins in module 3

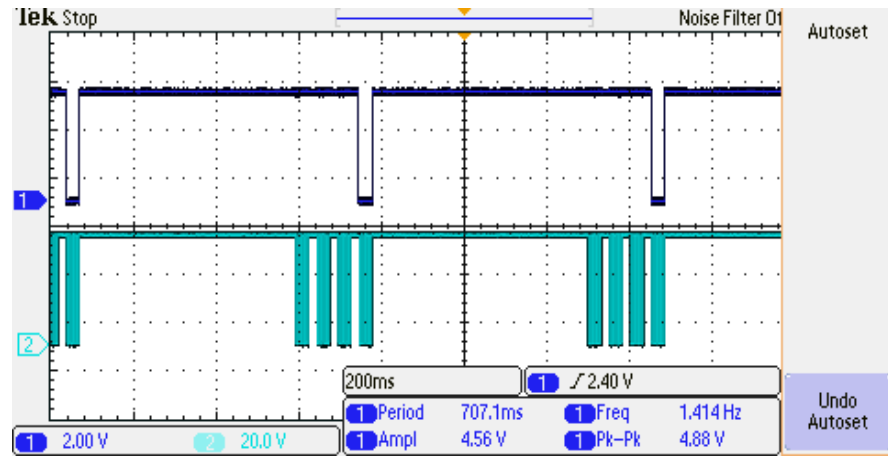

Fig. 15. Measurement results on CS and SCK pins in module 4

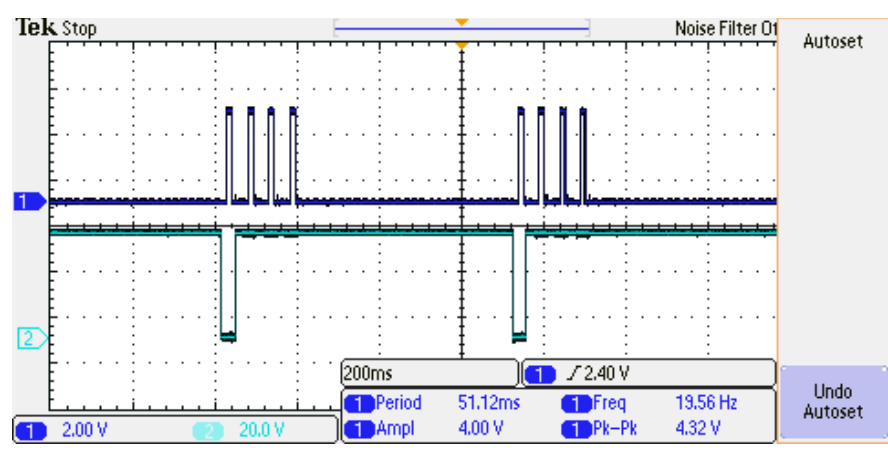

Fig. 16. Measurement results on SO and CS pins in module 1

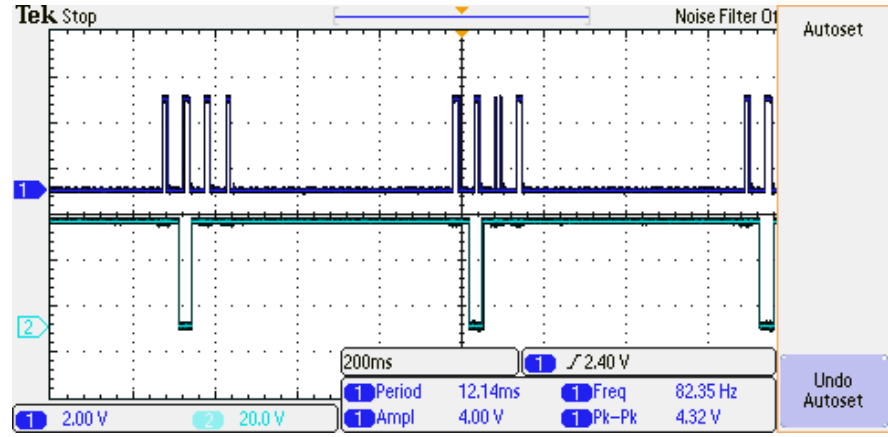

Fig. 17. Measurement results on SO and CS pins in module 2

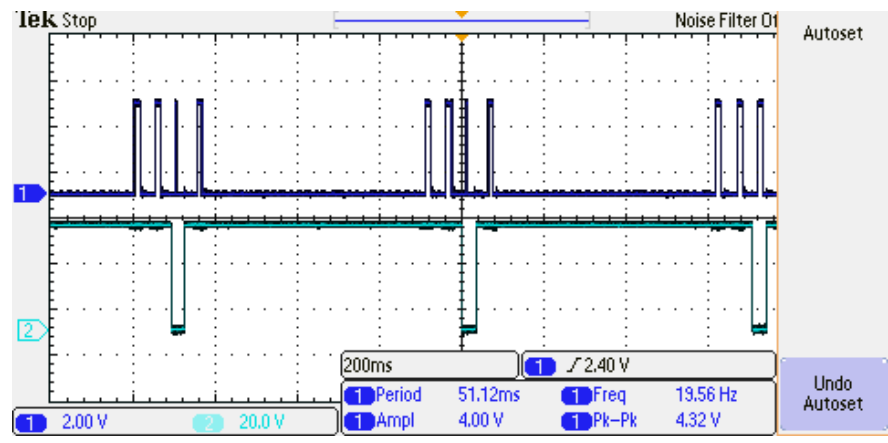

Fig. 18. Measurement results on SO and CS pins in module 3 
IJEEMI, Vol. 1, No. 2, November 2019, pp:65-70

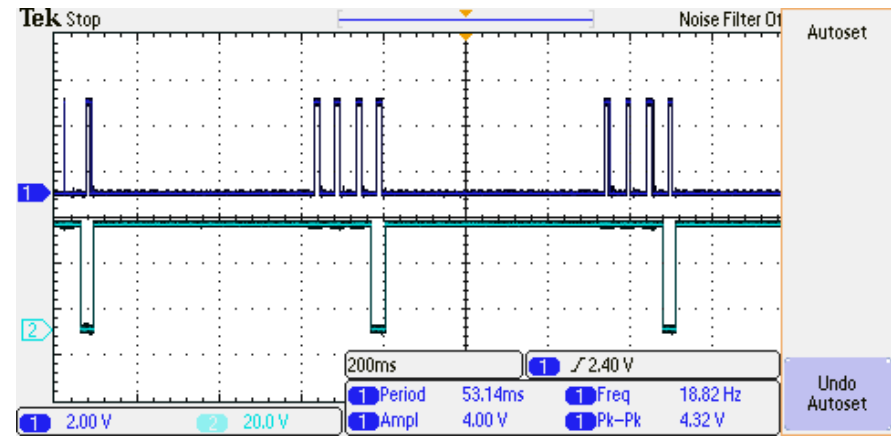

Fig. 19. Measurement results on SO and CS pins in module 4

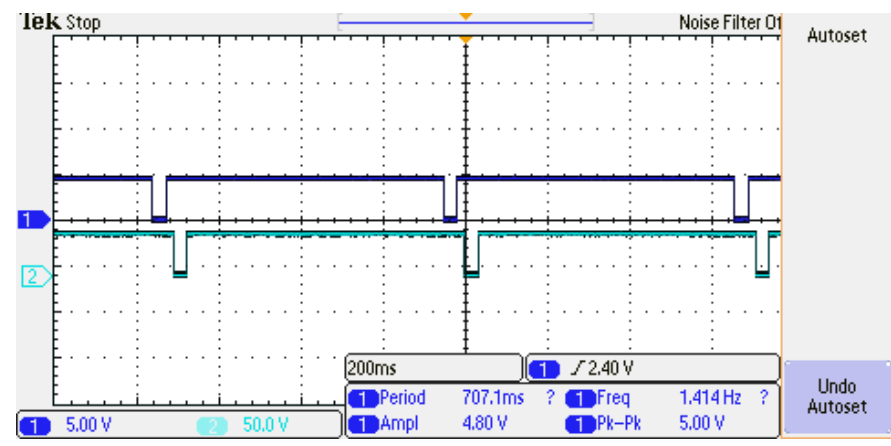

Fig. 20. Measurement results on CS module 1 pin and CS module 2 pin

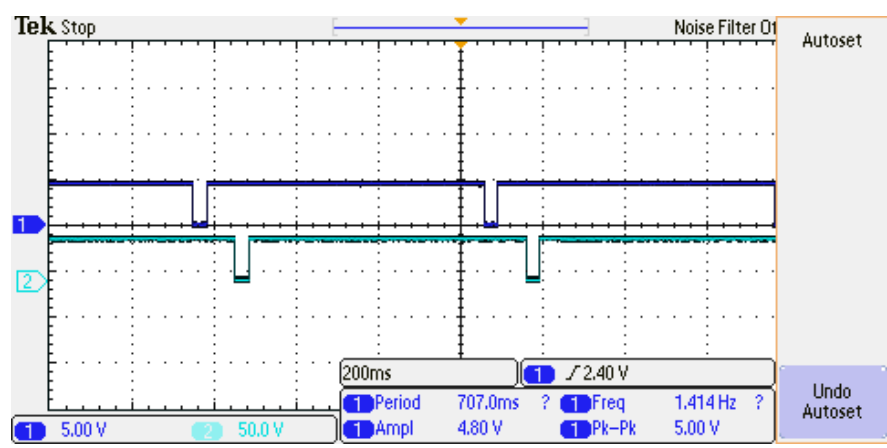

Fig. 21. Measurement results on CS module 1 pin and CS module 3 pin

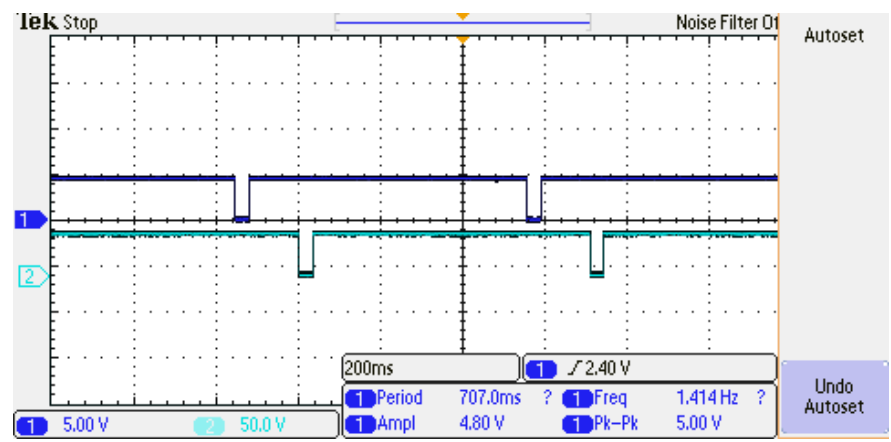

Fig. 22. Measurement results on CS module 1 pin and CS module 4 pin

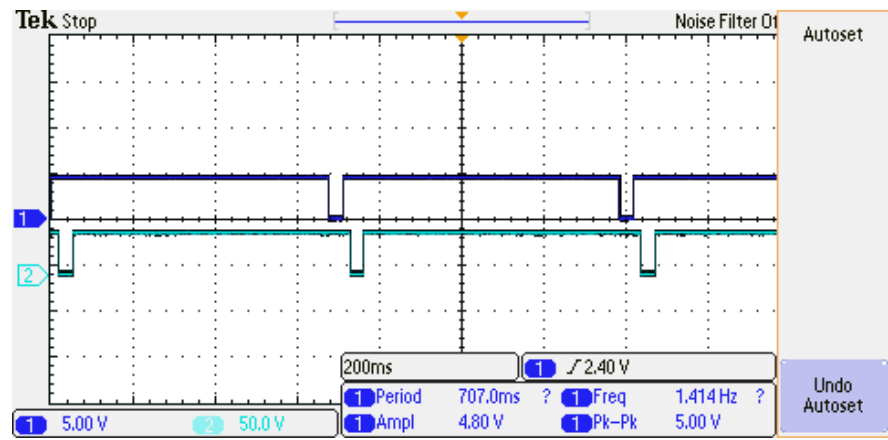

Fig. 23. Measurement results on CS module 2 pin and CS module 3 pin

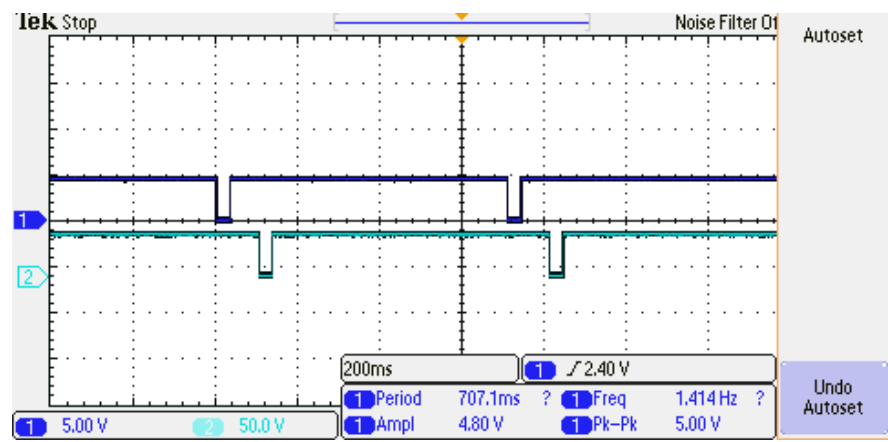

Fig. 24. Measurement results on CS module 2 pin and CS module 4 pin

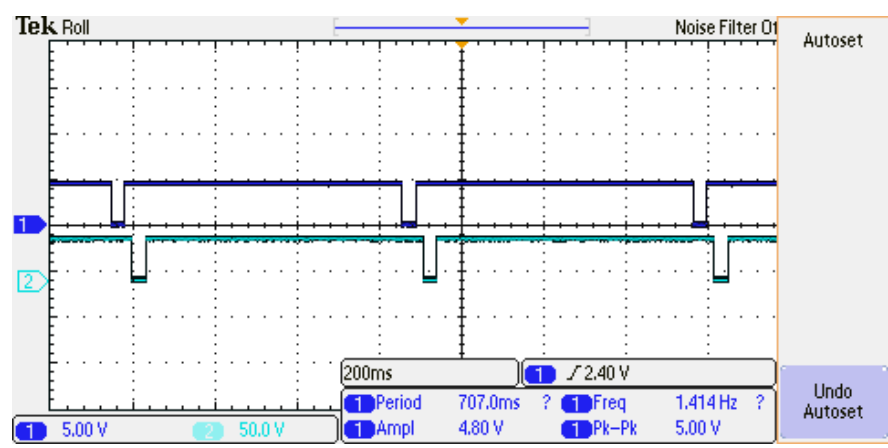

Fig. 25. Measurement results on CS module 3 pin and CS module 4 pin

4) The Error of temperature measurement results

The validation of the results of temperature measurements that appear on the character LCD are compared with the results of measuring the temperature by the Madgetech temperature calibrator OctTemp2000. The error was showed in Table I. 
TABLE I. THE ERROR OF MEASUREMENT FOR TEMPERATURE MEASUREMENT RESULTS BETWEEN THE DESIGN AND CALIBRATOR.

\begin{tabular}{ccc}
\hline Temperature & Sensor & Error \\
\hline 50 & T1 & $1.4 \%$ \\
& T2 & $1.2 \%$ \\
& T3 & $2.3 \%$ \\
& T4 & $1.1 \%$ \\
\hline \multirow{2}{*}{100} & T1 & $1.8 \%$ \\
& T2 & $1.9 \%$ \\
& T3 & $0.2 \%$ \\
& T4 & $0.2 \%$ \\
\hline 150 & T1 & $3.1 \%$ \\
& T2 & $4.4 \%$ \\
& T3 & $1.3 \%$ \\
& T4 & $1.3 \%$ \\
\hline
\end{tabular}

\section{Discussion}

Based on the results of the discussion and the purpose of making the module it was found that the circuit and the program can read the temperature and the microcontroller program can process the data to be displayed on the character LCD. Modules can do temperature readings using a $\mathrm{K}$ type thermocouple which is processed using the MAX6675 module and can convert temperature from Celsius to Farenheit and Kelvin. Data collection was carried out at BPFK using modules at $50^{\circ} \mathrm{C}, 100$ ${ }^{\circ} \mathrm{C}$ and $150^{\circ} \mathrm{C}$. The module has the smallest error $0.2 \%$ on $\mathrm{T} 3$ and T4 when measuring $100{ }^{\circ} \mathrm{C}$, and the biggest is $4.4 \%$ at $\mathrm{T} 2$ when measuring $150^{\circ} \mathrm{C}$ when compared to the results of reading a standard calibration tool. The smallest reading that the module can do is $0.25^{\circ} \mathrm{C}$

\section{CONClusion}

This study has demonstrated the development of sterilizing calibrators. This study is based on Arduino microcontroller and some modules for processing data. This study has proofed that the accuracy is not possible to use as a temperature calibrator, because the minimum reading is too large. In the future, this study is expected to use a better module to conduct temperature readings with smaller data and equipped with a data logger whose results can be displayed as a graph.

\section{REFERENCES}

[1] M. Sofyan, "Alat Kalibrasi Suhu dengan Thermocouple dilengkapi Thermohygrometer," 2016.

[2] D. Mussetyarsih, "Data Logger Temperature Meter pada Autoclave," 2015.

[3] R. B. Primaswara, "Data Logger Temperature Meter Pada Sterilisator Kering," 2016.
[4] D. Liu, P. shi, W. Ren, Y. Liu, G. Niu, M. Liu, N. Zhang, B. Tian, W. Jing and Z. Jiang, "A New Kind of Thermocouple Made of p-Type and n-Type SemiConductive Oxides with Giant Thermoelectric Voltage for High," Journal of Materials Chemistry C, p. 5, 2018.

[5] I. K. Purohit and N. V. Gupta, "Temperature Mapping of Hot Air Oven (Dry Heat Sterilizer)," Journal of Pharmacy Research, vol. 11, no. 2, pp. 120-123, 2017. 